\title{
Factors affecting the implementation of government air pollution reduction and elimination policy: a case study of Map Ta Phut industrial estate, Rayong Province, Thailand
}

\author{
S. Vajirakachorn \\ School of Social and Environmental Development, \\ National Institute of Development Administration, Thailand
}

\begin{abstract}
This study aims at finding factors affecting and enabling us to predict the achievement of policy implementation of government since the announcement of a pollution-control zone in Map Ta Phut industrial estate. This research collected data from 157 industrial factories in the Map Ta Phut industrial estate. The data collection process used a questionnaire. The survey data was analyzed by using frequency, percentage, mean, standard deviation, Pearson's Correlation Coefficient, and Multiple Regression Analysis. The main results showed that: 1) The achievement of government air pollution reduction and elimination policy implementation was at a high level; 2) According to the results from Multiple Regression Analysis, only 4 independent variables, including the developing of an action plan, campaigning and public relations, participation of workers, and availability of resources, coordinately were able to predict the achievement in policy implementation at the overall level with $67.7 \%$ correctness. The campaigning and public relations were the first predictor.

Keywords: policy implementation, air pollution policy, Map Ta Phut industrial estate.
\end{abstract}

\section{Introduction}

The Map Ta Phut industrial estate is a large industrial park located in Mueng District, Rayong Province. The policy to create Map Ta Phut industrial estate 
was formulated in 1981 after exploration activities in the Gulf of Thailand found natural gas. The construction work started in 1987 and was finished by 1990 . This was a proactive strategy in developing the country during the period of the $5^{\text {th }}$ National Economic and Social Development plan (B.E.2525-2529) [1]. As the industrial sector grew, there was no effective control of pollutants released by factories to be in line with the law. In addition, the turning of residential areas into industrial areas caused the buffer zone to disappear and led to many problems including the problem of industrial pollution, the danger of chemical leaks, and lack of confidence on the part of people resulting in complaints from the community. The problem of chemical leaks started in June 1996 with the problem of unpleasant smells of gas released by the refinery of Star Petroleum Refining Company Limited. In 1997, Rayong Provincial Health Office coordinated with the Map Ta Phut Industrial Estate to investigate the refinery and nearby factories to control the release of sulfur dioxide into the atmosphere. However, circumstances worsened when teachers and students of Map Ta Phut Pittayakarn School in Mueng District, Rayong Province were exposed to strong chemical smells produced by nearby factories on 23 June 1997. Forty students suffered from various symptoms including headache, vomiting and chest pain. Some cases were so severe that they had to be admitted into hospital. Later, the school had to be closed and moved to the other location.

In 2005, Greenpeace Southeast Asia inspected air pollution in the Map Ta Phut industrial areas and found that the level of volatile organic compounds (VOCs) such as vinyl chloride, dichloroethane and chloroform, exceeded the air quality screening level of US-EAP (EPA Region 6 Screening Level) of the United States [2]. This indicated that the air quality in Map Ta Phut areas was in crisis and that people were at risk of developing cancer. The Pollution Control Department, therefore, investigated the information and found that the information was accurate. After that the National Environment Board suggested that the Ministry of Natural Resources and Environment consider the feasibility of declaring Map Ta Phut as a pollution control area. Later, the National Environment Board resolved to appoint an ad hoc sub-committee to address the pollution problem and regulate the development of the areas in Rayong province with respect to pollution control. An operational plan to reduce and eliminate pollution in Rayong province from 2007 to 2011 was created.

The fact that Map Ta Phut was not declared as a pollution control area led the people, communities and private development organizations launching an appeal because they disagreed with the solution. On October 2007, 27 residents from 11 communities in the Map Ta Phut industrial estate decided to file a complaint to the National Environment Board asking the board to declare Map Ta Phut as a pollution control area but received no answer. Therefore, they filed a lawsuit with the Administrative Court against the National Environment Board claiming that the board was negligent in their duties as determined by the Enhancement and Conservation of National Environment Quality Act, B.E. 2535 because the board did not declare Tambon (subdistrict) Map Ta Phut and Map Ta Phut municipality and nearby areas as a pollution control area. On 3 March 2009, the Rayong Administrative Court ruled that the National Environment Board was 
negligent in not announcing the Map Ta Phut industrial estate and nearby areas as a pollution control area. Later on 30 September 2009, the Central Administrative Court demanded that the 76 new projects in the Map Ta Phut industrial estate be suspended stating that governmental units approved these projects while failing to comply with Section 67 (2) of the Constitution B.E. 2550 which holds that any project or activity which may seriously affect a community's environmental quality, its natural resources or its people's health, is prohibited unless these environmental and health impacts are studied and assessed; public hearings process are held to obtain the opinions of people and stakeholders; and independent organizations provide opinions and comments prior to the implementation of such project or activity [3].

This paper will explore in further detail of the implementation of the air pollution reduction and elimination policy of the government, including the declaration of Tambon Map Ta Phut and nearby areas as a pollution control area, the resolution of the problem of adhering to Section 67 (2) of the Thai Constitution B.E. 2550, the approval of urgent projects to address people's problems and reduce and eliminate pollution in 32 projects in Map Ta Phut and nearby areas totaling 1,432 million baht starting from December 2009. In order to measure the implementation achievement, the main unit of analysis is the industrial factories in the Map Ta Phut pollution control area. The purposes of the study include: 1) To measure the overall achievement of policy implementation in reducing and eliminating air pollution produced by industrial factories in the Map Ta Phut industrial estate, and 2) To study factors affecting and enabling to predict the achievement of policy implementation in reducing and eliminating air pollution produced by industrial factories in the Map Ta Phut industrial estate.

\section{Research framework and methodology}

This research was based on the conceptual framework of policy implementation study which followed Pressman and Wildavsky [4] work as the pioneers. Most of the policy implementation research was focused on the causal relation between affecting factors and achievement of policy implementation. Van Meter and Van Horn [5], for instance, proposed two groups of factors that shape the linkage between policy and performance. The first group is the policy related factors, including policy standards and objectives and availability of resource. The second group is concerned with the policy process, comprising of interorganizational communication and enforcement activities, the characteristics of the implementing agency, economic, social, and political conditions, and the disposition of implementers.

Mazmanian and Sabatier [6] quoted a set of six conditions of effective policy implementation. They are: 1) policy objectives are clear and consistent, 2) the program is based on valid causal theory, 3) the implementation process is structured adequately, 4) implementing officials are committed to the program's goals, 5) interest groups and executives and legislative sovereigns are supportive, 
and 6) there are no detrimental changes in the socioeconomic framework conditions.

In addition, Chandarasorn [7] presented a policy implementation model that was applied from the organizational development model. It focuses on five different factors affecting the performance of policy implementation, which are (1) motivation; (2) leadership; (3) people's participation; (4) teamwork; and (5) commitment.

Lastly, Edwards [8] proposed four critical factors or variables in implementing public policy: communication, resources, dispositions or attitudes, and bureaucratic structure.

In this research, the proposed factors that are expected to contribute to the achievement of policy implementation in reducing and eliminating air pollution produced by industrial factories in the Map Ta Phut industrial estate are based on those researches that we just mentioned combined with some research from Thai scholars, such as Jhermpun [9], Chompucot [10], and Trakarnvanich [11]. The suggested model can be expressed in the following equation:

Achievement of Policy Implementation $=\mathrm{b} 0+\mathrm{b} 1$ (Government Policy) +b2 (Leadership) + b3 (Personal Quality) + b4 (Work Control) + b5 (Goals and

Objectives) + b6 (Developing an Action Plan) + b7 (Campaigning and Public

Relations) + b8 (Availability of Resources) + b9 (Efficiency of the Machine) + b10 (Awareness) + b11 (Participation of Worker)

The research method included a study of secondary data gathered from literature review and a study of primary data gathered by using questionnaires. The sample of this study were personnel who worked for one of the 157 industrial factories in the Map Ta Phut pollution control area and were responsible for managing air pollution. Data collection process used questionnaire by classifying factors into; 1) government policy, 2) executives' leadership and how well they assigned tasks, 3) personal quality, 4) work control, 5) goals and objectives, 6) developing an action plan by the factory, 7) campaigning and public relations 8) availability of resources 9) efficiency of the machine 10) awareness of air pollution reduction and elimination, and 11) participation of worker. The output dependent variable was the achievement of policy implementation of government air pollution reduction and elimination policy, measured by 2 sub-dimensions, including 1) the effectiveness in policy implementation and 2) the continuity of policy implementation. The statistics approaches were mean, standard deviation, Pearson's Correlation Coefficient, and Multiple Regression Analysis.

\section{The achievement of policy implementation and affecting factors}

\subsection{Descriptive data related to independent and dependent factors}

From the above 11 independent factors, data from the questionnaire revealed that efficiency of the machine received the highest average score (3.25) followed by 
participation of worker (3.21), executives' leadership and developing an action plan by the factory received the same score (3.00), awareness of air pollution reduction and elimination (2.98), personal quality, work control, and goals and objectives received the same score (2.90), availability of resources and government policy received the same score (2.80), and campaigning and public relations (2.66), respectively. In addition, the overall average score of the achievement of policy implementation of government air pollution reduction and elimination policy which is the dependent factor was at a high level (2.95) with the 2 sub-dimensions equal to 2.98 for the effectiveness in policy implementation and 2.93 for the continuity of policy implementation. The results are shown in Table 1.

Table 1: The descriptive results of independent and dependent factors.

\begin{tabular}{|l|c|c|}
\hline \multicolumn{1}{|c|}{ Factors } & $\overline{\mathrm{x}}$ & $S D$ \\
\hline Independent factor: & & \\
1) government policy & 2.80 & 0.531 \\
2) executives' leadership & 3.00 & 0.741 \\
3) personal quality & 2.90 & 0.715 \\
4) work control & 2.90 & 0.715 \\
5) goals and objectives & 2.90 & 0.732 \\
6) developing an action plan by the factory & 3.00 & 0.752 \\
7) campaigning and public relations & 2.66 & 0.782 \\
8) availability of resources & 2.80 & 0.809 \\
9) efficiency of the machine & 3.25 & 0.657 \\
10) awareness of air pollution reduction and elimination & 2.98 & 0.703 \\
11) participation of worker & 3.21 & 0.649 \\
\hline Dependent factor: & & \\
1) the achievement of policy implementation & 2.95 & 0.567 \\
1.1) the effectiveness in policy implementation & 2.98 & 0.448 \\
1.2) the continuity of policy implementation & 2.93 & 0.838 \\
\hline
\end{tabular}

$\begin{array}{lll}\text { Remark: } & \text { The average of } & 0-1.33 \text { means low } \\ & \text { The average of } & 1.34-2.66 \text { means medium } \\ & \text { The average of } & 2.67-4.00 \text { means high }\end{array}$

\subsection{Affecting factors on policy implementation}

To determine the relative importance of factors affecting the achievement of policy implementation of government air pollution reduction and elimination policy in the Map Ta Phut industrial estate, we followed a two-step analysis by using both standard and stepwise multiple regression. First, standard multiple regression analysis was conducted to evaluate how well the 11 independent factors predicted the achievement of policy implementation. The linear combination of 11 independent factors was significantly related to the achievement of policy implementation, $\mathrm{F}=27.039, \mathrm{p}<0.001$. The multiple correlation coefficient was 0.831 , indicating that approximately $69.1 \%$ of the 
variance of the achievement of policy implementation could be accounted for by the linear combination of 11 factors (Table 2).

When considering on each factor, the coefficient for government policy, executives' leadership, personal quality, and awareness of air pollution reduction and elimination were found to be negative and not statistically significant. The coefficient for work control, goals and objectives, developing an action plan by the factory, and efficiency of the machine were positive and not statistically significant. Controlling for other factors, the campaigning and public relations, availability of resources, and participation of worker were statistically significant at the 0.05 level in a one-tailed test, and its sign were in the expected direction. The regression equation for predicting the achievement was:

Achievement of Policy Implementation $=0.982-0.056$ (Government Policy)

- 0.030 (Leadership) - 0.072 (Personal Quality) + 0.111(Work Control)

+0.038 (Goals and Objectives) + 0.137 (Developing an Action Plan)

+0.169 (Campaigning and Public Relations) + 0.151(Availability of Resources)

+0.055 (Efficiency of the Machine) - 0.074(Awareness)

+0.213 (Participation of Worker)

Table 2: $\quad$ The Standard Multiple Regression Analysis of factors affecting the achievement of policy implementation.

\begin{tabular}{|c|c|c|c|c|}
\hline Variables & B & Beta & $\mathbf{t}$ & $\mathbf{P}$ \\
\hline CONSTANT & 0.982 & & 4.813 & $0.000 * * *$ \\
\hline government policy & -0.056 & -0.056 & -1.097 & 0.274 \\
\hline executives' leadership & -0.030 & -0.040 & -0.459 & 0.647 \\
\hline personal quality & -0.072 & -0.090 & -1.115 & 0.267 \\
\hline work control & 0.111 & 0.153 & 1.417 & 0.159 \\
\hline goals and objectives & 0.038 & 0.050 & 0.481 & 0.631 \\
\hline $\begin{array}{l}\text { developing an action } \\
\text { plan by the factory }\end{array}$ & 0.137 & 0.185 & 1.599 & 0.112 \\
\hline $\begin{array}{l}\text { campaigning and public } \\
\text { relations }\end{array}$ & 0.169 & 0.256 & 2.835 & $0.005 * *$ \\
\hline availability of resources & 0.151 & 0.226 & 2.313 & $0.022 *$ \\
\hline $\begin{array}{l}\text { efficiency of the } \\
\text { machine }\end{array}$ & 0.055 & 0.061 & 0.847 & 0.399 \\
\hline $\begin{array}{l}\text { awareness of air } \\
\text { pollution reduction and } \\
\text { elimination }\end{array}$ & -0.074 & -0.093 & -1.051 & 0.295 \\
\hline participation of worker & 0.213 & 0.247 & 3.085 & $0.002 * *$ \\
\hline \multicolumn{5}{|c|}{$\begin{array}{l}\mathrm{R}=0.831 \mathrm{a}, \mathrm{R}^{2}=0.691, \text { Adj. } \mathrm{R}^{2} 0.665, \text { Durbin-Watson }=1.775 \\
\mathrm{~F}=27.039, \text { Sig. }=0.000 \mathrm{a}(* \mathbf{p}<\mathbf{0 . 0 5}, * * \mathbf{p}<\mathbf{0 . 0 1}, * * \mathbf{p}<\mathbf{0 . 0 0 1})\end{array}$} \\
\hline
\end{tabular}

Second, a stepwise multiple regression analysis was conducted to evaluate whether all 11 factors were necessary to predict the achievement of policy implementation. Level of $F$ to enter and $F$ to remove were set to correspond to $p$ 
level of 0.005 and 0.01 , respectively, to adjust for family wise alpha error rates associated with multiple significant tests. Results of the stepwise multiple regression analysis provided partial confirmation for the research model: rate of the achievement of policy implementation is a linear function of the developing an action plan by the factory, campaigning and public relations, participation of worker, and availability of resources, $F=73.427, p<0.001$. The multiple correlation coefficient was 0.823 , indicating that approximately $67.7 \%$ of the variance of the achievement of policy implementation could be account for by the developing an action plan by the factory, campaigning and public relations, participation of worker, and availability of resources. Standardized beta weights were 0.214 for the developing an action plan by the factory, 0.300 for campaigning and public relations, 0.197 for participation of worker, and 0.238 for availability of resources. Thus the regression equation for predicting the achievement of policy implementation was:

Achievement of Policy Implementation $=0.899+0.158$ (Developing an Action Plan) +0.198 (Campaigning and Public Relations) +0.159 (Availability of Resources) +0.170 (Participation of Worker)

As shown in Table 3 and regression equation, the standardized regression coefficient of the campaigning and public relations turn out to be the most important factor in determining overall achievement of policy implementation. The next influential factor are the availability of resources, the developing an action plan by the factory, and participation of worker, respectively.

Table 3: The Stepwise Multiple Regression Analysis of factors affecting the achievement of policy implementation.

\begin{tabular}{|c|c|c|c|c|}
\hline Variables & B & Beta & $\mathbf{t}$ & $\mathbf{p}$ \\
\hline CONSTANT & 0.899 & & 6.339 & 0.000 \\
\hline $\begin{array}{l}\text { developing an action plan } \\
\text { by the factory }\end{array}$ & 0.158 & 0.214 & 2.429 & $0.016^{*}$ \\
\hline $\begin{array}{l}\text { campaigning and public } \\
\text { relations }\end{array}$ & 0.198 & 0.300 & 3.649 & $0.000 * * *$ \\
\hline participation of worker & 0.170 & 0.197 & 3.213 & $0.002 * *$ \\
\hline availability of resources & 0.159 & 0.238 & 2.974 & $0.003 * *$ \\
\hline \multicolumn{5}{|c|}{$\begin{array}{l}\mathrm{R}=0.823 \mathrm{~d}, \mathrm{R}^{2}=0.677, \text { Adj. } \mathrm{R}^{2}=0.668, \text { Durbin-Watson }=1.741 \\
\mathrm{~F}=73.427, \text { Sig. }=0.000 \mathrm{a}(\boldsymbol{*} \mathbf{p}<\mathbf{0 . 0 5}, * * \mathbf{p}<\mathbf{0 . 0 1}, * * * \mathbf{p}<\mathbf{0 . 0 0 1})\end{array}$} \\
\hline
\end{tabular}

\section{Conclusion and discussion}

The major hypothesis of this study was that the achievement of policy implementation in reducing and eliminating air pollution produced by industrial factories in the Map Ta Phut industrial estate would vary according to the level of 11 independent factors, such as government policy, executives' leadership, 
personal quality, work control, goals and objectives, developing an action plan by the factory, and efficiency of the machine, and so on.

According to the result from standard multiple regression analysis, 11 factors could predict the achievement in overall level with $69.1 \%$ correctness. However, when stepwise multiple regression analysis was employed, only 4 independent factors, including the developing an action plan by the factory, campaigning and public relations, participation of worker, and availability of resources, coordinately were able to predict the achievement with the degree of correctness up to $67.7 \%$. The campaigning and public relations were the first predictor.

Since the conceptual framework proposed in this study was derived from several research works that we already mentioned earlier, these finding generally support in some part of those policy implementation models developed by Van Meter and Van Horn [5] which focusing on policy standards and objectives, availability of resource, inter-organizational communication and enforcement activities, the characteristics of the implementing agency, economic, social, and political conditions, and the disposition of implementers, Mazmanian and Sabatier [6], which including six conditions; clear and consistent policy objectives, the program is based on valid causal theory, the implementation process is structured adequately, implementing officials are committed to the program's goals, interest groups and executives and legislative sovereigns are supportive, and the socioeconomic framework conditions, Chandarasorn [7] focusing on motivation, leadership, people's participation, teamwork, and commitment, and Edwards [8], including communication, resources, dispositions or attitudes, and bureaucratic structure.

\section{Recommendation}

It was shown from this study that there are four factors, including the developing an action plan by the factory, campaigning and public relations, participation of worker, and availability of resources which influence to the achievement of policy implementation in reducing and eliminating air pollution produced by industrial factories in the Map Ta Phut industrial estate and can lead to its improvement. Based on those factors, the following are recommendation for improving the performance of the factories and for overall policy implementation:

1) The implementing agency should support the factory in the development of an action plan for the reducing and eliminating of air pollution produced within the factory. The plan should cover all managerial aspects and approaches to solve the problem.

2) The implementing agency should set up an independent information agency whose duties would be to collect and compile data concerning with the air pollution problem within the Map Ta Phut industrial estate area, and then generate these data as available information. The existence of such information would help the factory in accessing and improving the current situation more effectively. 
3) The implementing agency should arrange and provide monitoring systems so that the factory could be checked to see what they have done and to see whether they have any problems and provide some solutions for such problems.

4) The implementing agency should reward the outstanding factory in reducing and eliminating of air pollution produced and ask the factory to be the best practice factory to share the experience with other factories.

5) Executives at the factory should focus on participation management by coordinating with the workers in implementing their own action plan.

6) It cannot be denied that resources (financial, technical, and human) are important for the achievement of policy implementation. Therefore, the executives at the factory should support more resource for the implementation of air pollution reducing and eliminating within their own factory.

7) The campaigning and public relations should be improved. Implementing agency should encourage the factory to formulate the campaigning and public relations plan and set up a working group to look over and lunch the campaigning and public relations activities more frequently and effectively.

\section{References}

[1] Office of the National Economic and Social Development Board. The $5^{\text {th }}$ National Economic and Social Development Plan, B.E.25252529, www.nesdb.go.th/Default.aspx?tabid=87

[2] Campaign for Alternative Industry Network (CAIN), Greenpeace Southeast Asia (GPSEA), and Global Community Monitor (GCM). Thailand's Air: Poison Cocktail, 2005.

[3] Kanchanachitra, C. (ed.), Thai Health 2010: Capitalism in Crisis: Opportunity for Society? Institute for Population and Social Research, Mahidol University: Nakhon Pathom, pp. 42-45, 2010.

[4] Pressman, J.L. \& Wildavsky, A., Implementation, University of California Press: Berkeley, 1973.

[5] Van Meter, D. \& Van Horn, C., The policy implementation process: a conceptual framework. Administration \& Society, 6 (February), pp. 445488, 1975.

[6] Mazmanian, D. A. \& Sabatier, P.A., Implementation and Public Policy, Scott, Foresman, and Company: Glenview, 1983.

[7] Chandarasorn, V., An Integrated Theory of Public Policy Implementation, TURA.: Bangkok, 2005. (In Thai)

[8] Edwards, G.C., Implementing Public Policy, Congressional Quarterly Press: Washington, DC, 1980.

[9] Jhermpun, S., The Policy Implementation Success of Energy Saving in Public Sector, doctoral dissertation, Ramkhamhaeng University, 2009. (In Thai) 
704 Environmental Impact II

[10] Chompucot, C., Major Factors Affecting Educational Policy Implementation Effectiveness for the Three Southernmost Province of Thailand as Perceived by School Directors, doctoral dissertation, National Institute of Development Administration, 2011. (In Thai)

[11] Trakarnvanich, B., Performance Based Budgeting System: A Study of Poverty Reduction Policy Implementation in Thailand, doctoral dissertation, National Institute of Development Administration, 2011. (In Thai) 